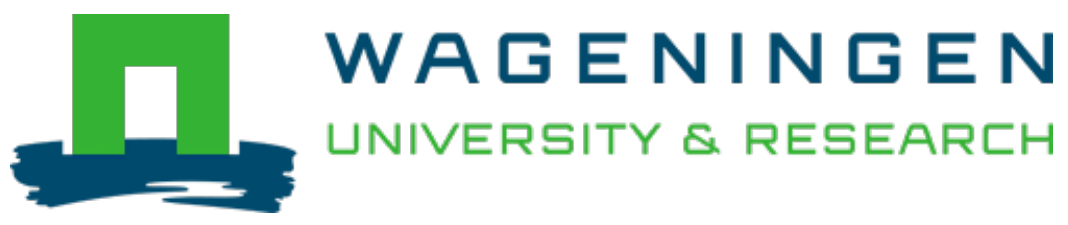

\title{
A socio-spatial index for risk management in shrimp aquaculture across landscapes
}

\author{
Aquaculture \\ Lien, Ho Hong; Mey, Yann; Bush, Simon R.; Meuwissen, Miranda P.M. \\ https://doi.org/10.1016/j.aquaculture.2020.735861
}

This publication is made publicly available in the institutional repository of Wageningen University and Research, under the terms of article $25 \mathrm{fa}$ of the Dutch Copyright Act, also known as the Amendment Taverne. This has been done with explicit consent by the author.

Article 25 fa states that the author of a short scientific work funded either wholly or partially by Dutch public funds is entitled to make that work publicly available for no consideration following a reasonable period of time after the work was first published, provided that clear reference is made to the source of the first publication of the work.

This publication is distributed under The Association of Universities in the Netherlands (VSNU) 'Article $25 \mathrm{fa}$ implementation' project. In this project research outputs of researchers employed by Dutch Universities that comply with the legal requirements of Article $25 \mathrm{fa}$ of the Dutch Copyright Act are distributed online and free of cost or other barriers in institutional repositories. Research outputs are distributed six months after their first online publication in the original published version and with proper attribution to the source of the original publication.

You are permitted to download and use the publication for personal purposes. All rights remain with the author(s) and / or copyright owner(s) of this work. Any use of the publication or parts of it other than authorised under article $25 \mathrm{fa}$ of the Dutch Copyright act is prohibited. Wageningen University \& Research and the author(s) of this publication shall not be held responsible or liable for any damages resulting from your (re)use of this publication.

For questions regarding the public availability of this publication please contact openscience.library@wur.nl 


\title{
A socio-spatial index for risk management in shrimp aquaculture across landscapes
}

\author{
Ho Hong Lien ${ }^{\mathrm{a}, \mathrm{b}, *}$, Yann de Mey ${ }^{\mathrm{a}}$, Simon R. Bush ${ }^{\mathrm{c}}$, Miranda P.M. Meuwissen ${ }^{\mathrm{a}}$ \\ ${ }^{\text {a }}$ Business Economics Group, Wageningen University \& Research, the Netherlands \\ ${ }^{\mathrm{b}}$ Department of Accounting and Auditing, College of Economics, Can Tho University, Viet Nam \\ ${ }^{\mathrm{c}}$ Environmental Policy Group, Wageningen University \& Research, the Netherlands
}

\section{A R T I C L E I N F O}

\section{Keywords:}

Landscape governance

Production risks

Shared risk management

Structural equation modelling

Vietnam

\begin{abstract}
A B S T R A C T
Area-based management has been promoted to mitigate risks beyond the boundaries of aquaculture farms However, there remains no objective measure of the scale at which area-based management can most effectively control systemic production risks. There is also a lack of understanding of how the social connectivity between farmers operating in a given landscape or 'area' affects the shared risk perceptions and strategies of shrimp farmers. This paper addresses this gap by introducing a socio-spatial index (SSI) that enables the objective definition of area-based management based on the spatial extent of the social connectivity of shrimp farmers. The study explores how the SSI translates into individual and shared risk behaviour by using structural equation modelling. The results indicate that the SSI provides a generic measure for the socio-spatial extent of area-based aquaculture management and a specific means of determining the probability of farmers adopting shared mitigation strategies related to key risks like disease. The SSI provides the assessment and further development of spatially explicit risk management strategies for promoting responsible aquaculture production.
\end{abstract}

\section{Introduction}

Aquaculture is one of the fastest growing industries in Asia, having grown at an average annual rate of nearly $10 \%$ over the last three decades to now contribute more than $50 \%$ of global seafood production (FAO, 2018). Although the development of aquaculture has been associated with high and fast economic returns, production has been relatively unstable due to the impact of low quality of inputs and post larvae (Joffre et al., 2018a), water pollution (Anh et al., 2010) and disease occurrence (Thitamadee et al., 2016). Nearly all of these production risks are either directly or indirectly attributable to the surrounding environment in which aquaculture farms are embedded (Subasinghe et al., 2009; Bottema et al., 2019; Bush et al., 2010; Soto et al., 2008)

Recognizing the shared nature of production risks, government and NGOs have developed a range of 'beyond farm' management approaches for the aquaculture industry, including agro-ecology (Tomich et al., 2011), landscape management (Freeman et al. 2015), farmer clusters and cooperatives (Joffre et al., 2019), and more recently zonal and area-based management (Aguilar-Manjarrez et al., 2017; Henriques et al., 2017; Salama et al., 2016). All of these approaches require a high degree of collaboration among socially connected farmers that can enable information sharing and the coordination of key production activities in a given area, landscape or region, like stocking and water exchange (Aguilar-Manjarrez et al., 2017). Most recently area-based management has been promoted as a means of scaling up 'on farm' risk management strategies and/or coordinate shared risk management strategies between farms (and farmers) (Bush et al., 2019; Bottema et al., 2019; Meuwissen et al., 2019).

Yet despite the potential benefits of area-based management in mitigating risks beyond the boundaries of farms (Bottema et al., 2019), and the proliferation of area-based management approaches currently employed (e.g. aquaculture management area, bay management plans and disease management plans, see (Murray and Gubbins, 2016), there remains no standard quantifiable way of determining the spatial scale at which an 'area' should be defined. In addition, while the importance of cooperation among farmers is widely cited (Ha et al., 2013; Galappaththi and Berkes, 2015; Joffre et al., 2019; Bush et al., 2010; Umesh et al., 2010), most studies focus on individual rather than shared risk perception, risk attitude and risk management strategies of farmers and other actors (Ahsan, 2011; Bergfjord, 2009; Joffre et al., 2018b; Le and Cheong, 2010; Lebel et al., 2016; van Winsen et al., 2016; Meraner and Finger, 2017). By ignoring the role of shared risk perception, attitude and strategies, we argue that farmer practices that have an effect

\footnotetext{
* Corresponding author at: Business Economics Group, Wageningen University \& Research, the Netherlands.

E-mail address: ho.lienhong@wur.nl (H.H. Lien).
} 


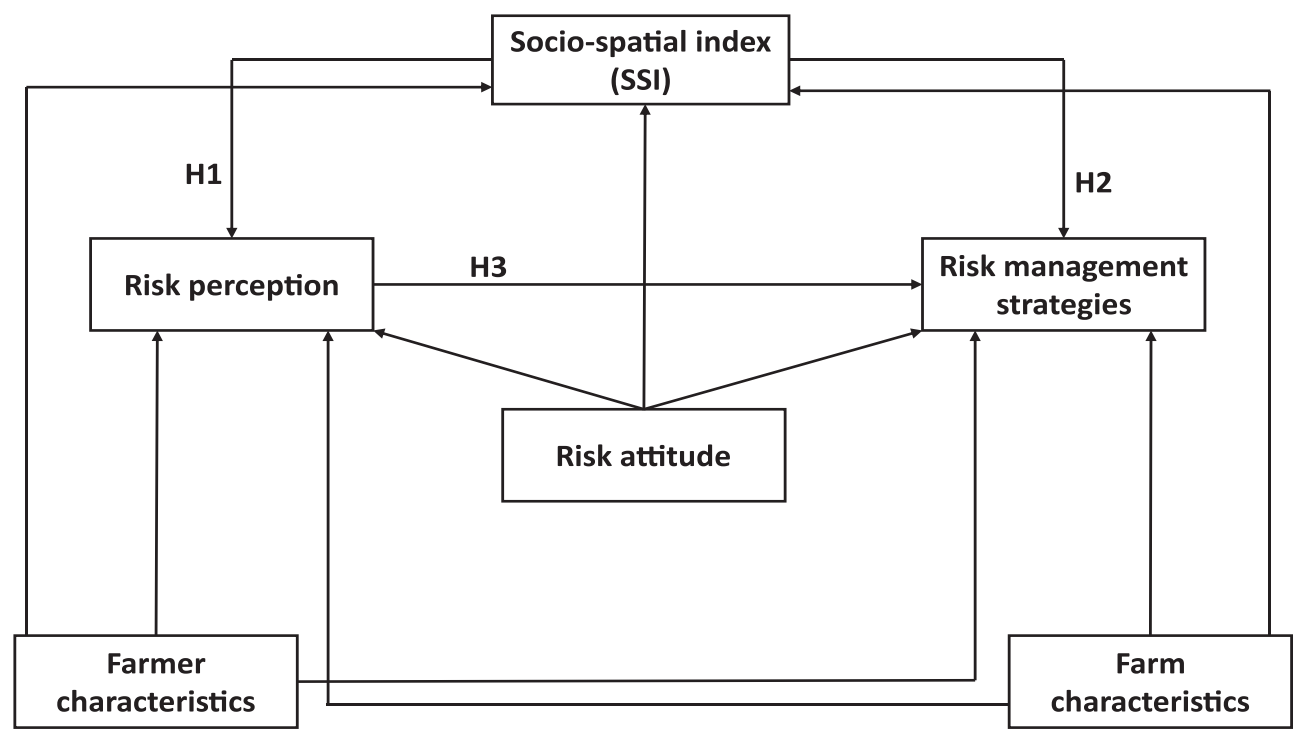

Fig. 1. Conceptual framework and research hypotheses. Hypothesis 1 (H1) and Hypothesis 2 (H2) indicate a positive association between the socio-spatial index and risk perception and risk management strategies adoption. Hypothesis 3 (H3) indicates that risk perception is positively associated with the adoption of risk management strategies. beyond the boundary of a farm are likely to be misrepresented.

Using shrimp aquaculture in Vietnam as a case study, we address this research gap by introducing a socio-spatial index (SSI) that enables an objective and quantifiable definition of area-based management based on the spatial extent of social connectivity between farmers oriented to mitigating shared risk in a given area. The value of the SSI is two-fold. First, it provides insights to both individual and shared risk behaviour. Second, it offers a generalizable means of assessing the connection between shared risk management strategies based on sociospatial connectivity that can be used both in and beyond the aquaculture sector.

The paper is divided into four main parts. The following section explains the design and operationalization of the SSI based on an empirical survey of shrimp farming in Vietnam, including three key hypotheses of how the SSI relates to risk behaviour (i.e. risk perception, risk attitude, and risk management). We then present results testing these hypotheses. The final sections of the paper discuss the potential of the SSI on the implementation of area-based approaches to aquaculture management in Southeast Asia and beyond.

\section{Design, operationalization and key hypotheses of the socio- spatial index (SSI)}

The concept of socio-spatial connectivity emerges out of a relational understanding of how networks are formed and reproduced in space and time (Massey, 2005). As Arts et al. (2017) argue, this relational perspective opens up new approaches for landscape or area-based governance. Instead of management boundaries being drawn around pre-defined jurisdictions or biophysical categories, socio-spatial connectivity defines these boundaries based on where, when and how social actors coordinate action based on shared meanings and perceptions of risk (see for e.g. van Koppen and Bush, 2018; Allen et al., 2018; Fischer et al., 2019; Kamstra et al., 2019)

The definition of relational boundaries is fundamentally different to the top down definition of planned zones or top down management areas. As argued by Bottema et al. (2019), socially delineated areamanagement of shrimp aquaculture is dependent on how farmers anticipate the outcomes of shared and individual management decisions, faced with high levels of uncertainty. The delineation of relational spaces of risk can therefore be considered as inherently dynamic, shaped by the constantly changing risk perception of multiple farmers. Nevertheless, when risks are perceived to be held in common, and farmers coordinate management activities to minimize these risks, socio-spatial boundaries can be stabilized (enough) to constitute the definition of an area (Bear, 2013; Vandergeest et al., 2015).

The socio-spatial index (SSI) developed in this paper represents the relational space of shared risk management. In developing the SSI, we construct and combine the two composite indicators of social and spatial connectivity.

Social connectivity is measured by the extent to which farmers share information with their neighbours - defined by Bottema et al. (2019) and Aguilar-Manjarrez et al. (2017) as those sharing a common water source. Our measure of social connectivity is based on the assumption that the more information sharing the greater the connectivity (Benhabib et al., 2011). As such, the strength of connectivity is based on the exchange of information related to farming, as well as information related to everyday life. Here our assumption is that the totality of farming and everyday information exchanged will have a proportionate effect on the exchange of information about production risks such as the spread of disease, water exchange, buying feed, and selling shrimp.

Spatial connectivity is represented by the proximity of farmers communicating on shared risk strategies. We measure this proximity based on the minutes travelled between farms using a motorbike - the dominant form of transport used by farmers in the Mekong Delta of Vietnam (and in extension Southeast Asia). Transport time has been selected rather than mobile phone communication, given our field-observations that these farmers prefer face-to-face engagement when discussing issues related to production risk. This assumption is corroborated by Matous and colleagues (Matous, 2017; 2015); Matous et al., 2015 who demonstrate that physical mobility remains a precondition for (digital) information sharing in rural areas.

To determine the type of risk strategy deployed at the area level, we examine the relationship between the SSI, production risk perception, and the adoption of risk management strategies. Accordingly, we test three main hypotheses.

First, we expect the SSI to be positively associated with farmers' perception of production risk (Hypothesis H1 in Fig. 1). This is based on the assumption that risk perception can differ between individuals (van Winsen et al., 2016), and that the more social interactions farmers have within their spatial network the more information they will share (Meuwissen et al., 2019) and the greater their awareness and perception of production risks will be (Hunecke et al., 2017).

Second, we expect the SSI to be positively related to the adoption of on-farm risk management and risk-sharing strategies (Hypothesis $\mathrm{H} 2$ in Fig. 1). As argued by Meuwissen et al. (2019), the intention to cooperate around the implementation of risk management strategies increases as farmers improve their knowledge on production risks through close and regular social contact. Therefore, farmers in close 
proximity and with high social interaction are likely to adopt more both on-farm and shared risk management strategies.

Third, we expect risk perception to be positively associated with the adoption of on-farm risk management strategies and risk-sharing strategies (Hypothesis H3 in Fig. 1). Risk perception can differ among individual farmers because of the types of the risk the individual faces and/or the difference of subjective risk interpretation (van Winsen et al., 2016). Although other factors, such as quasi-voluntary requirements set by chain actors and finance providers, can influence farmer adoption of risk management strategies (Meuwissen et al., 2001), the perception of risk is widely shown to play an important role in driving and shaping the adoption of farmer risk management strategies (Bishu et al., 2018; Joffre et al., 2018b; Ahsan, 2011; Lebel et al., 2016). Therefore, individual farmers with a high perception of risk are expected to actively adopt risk management strategies to mitigate and share risk with other farmers.

In addition to our main hypotheses, we test the relationship of risk attitude on SSI, risk perception and risk management strategies (see Fig. 1). Risk attitude is widely recognized as a key factor in determining how farmers perceive and act in response to risk (van Winsen et al., 2016; Meuwissen et al., 2001; Meraner and Finger, 2017; Ahsan and Roth, 2010). We address risk attitude (i.e. the degree to which an individual is willing to take risk) by hypothesising that risk averse individuals have higher risk perceptions and are more likely to adopt multiple risk management strategies (van Winsen et al., 2016; Meraner and Finger, 2017). There is currently no hypothesis of risk attitude on our SSI, so we leave the effect to be empirically observed from our analysis.

Finally, we test the relationship of personal characteristics of farmers (age, education, shrimp experience, farmer group types) and farm characteristics (species, production system) with risk perception, risk management strategies and SSI. Previous studies have correlated these personal characteristics and farm characteristics with risk perception and risk management strategies (Lebel et al., 2016; Bishu et al., 2018; Meuwissen et al., 2001; van Winsen et al., 2016; Meraner and Finger, 2017; Ahsan, 2011; Joffre et al., 2018b; Joffre et al., 2019). However, it not clear how they shape relations of individual farmers in a given area. There is also currently no hypothesis of farm and farmer's characteristics on SSI, so also here we leave the effect to be empirically observed from our analysis (see Table 1 for a summary of our hypotheses and expected relationship among variables).

\section{Methodology}

\subsection{Data collection}

Data was collected through a survey of farmers in Ca Mau, Bac Lieu and Soc Trang; the main shrimp producing provinces in the Mekong Delta. Four production systems were included in the sample - intensive shrimp system (IS), semi-intensive shrimp system (SIS), improved extensive shrimp (IES) and integrated mangrove - shrimp system (IMS) (Table 2). These systems provide the most generalizable sample of the potential socio-spatial connectivity among shrimp farmers. Specific farmers were sampled from a selection of districts and communes representing the different production systems - determined by the volume and area of production. This resulted in a total sample of 313 farms (See supplementary materials S1 for more details regarding sample selection).

Our study focuses on production risks (e.g. related to disease risk, input and water risk) that affect the volumes and/or quality of production. Starting with the classification of risk management strategies by Hardaker et al., 2015 we distinguished two categories: on-farm risk management and risk-sharing strategies in the aquaculture sector. Onfarm risk management strategies refer to strategies where individual farmers' decisions determine how the impact of production risks on their production are mitigated or avoided. Risk-sharing strategies
Table 1

Hypothesized relationships between SSI, risk behaviour variables and farmer and farm characteristics.

\begin{tabular}{|c|c|c|}
\hline Variables & Relation & Sign \\
\hline \multirow[t]{3}{*}{ SSI } & Risk perception & + \\
\hline & $\begin{array}{l}\text { Adoption of on-farm risk management } \\
\text { strategies }\end{array}$ & + \\
\hline & Adoption of risk-sharing strategies & + \\
\hline \multirow[t]{2}{*}{ Risk perception } & $\begin{array}{l}\text { Adoption of on-farm risk management } \\
\text { strategies }\end{array}$ & + \\
\hline & Adoption of risk-sharing strategies & + \\
\hline \multirow[t]{4}{*}{ Risk attitude } & SSI & $+1-$ \\
\hline & Risk perception & + \\
\hline & $\begin{array}{l}\text { Adoption of on-farm risk management } \\
\text { strategies }\end{array}$ & + \\
\hline & Adoption of risk-sharing strategies & + \\
\hline \multicolumn{3}{|l|}{ Farmer characteristics } \\
\hline \multirow[t]{4}{*}{ Age } & SSI & + \\
\hline & Risk perception & + \\
\hline & $\begin{array}{l}\text { Adoption of on-farm risk management } \\
\text { strategies }\end{array}$ & + \\
\hline & Adoption of risk-sharing strategies & $+/-$ \\
\hline \multirow[t]{4}{*}{ Education } & SSI & + \\
\hline & Risk perception & - \\
\hline & $\begin{array}{l}\text { Adoption of on-farm risk management } \\
\text { strategies }\end{array}$ & - \\
\hline & Adoption of risk-sharing strategies & + \\
\hline \multirow[t]{5}{*}{ Shrimp experiences } & SSI & + \\
\hline & Risk perception & - \\
\hline & $\begin{array}{l}\text { Adoption of on-farm risk management } \\
\text { strategies }\end{array}$ & + \\
\hline & Adoption of risk-sharing strategies & + \\
\hline & SSI & $+/-$ \\
\hline \multirow[t]{3}{*}{ Membership of group } & Risk perception & $+/-$ \\
\hline & $\begin{array}{l}\text { Adoption of on-farm risk management } \\
\text { strategies }\end{array}$ & $+/-$ \\
\hline & Adoption of risk-sharing strategies & $+/-$ \\
\hline \multicolumn{3}{|l|}{ Farm characteristics } \\
\hline \multirow[t]{4}{*}{ Intensity of production system } & SSI & $+1-$ \\
\hline & Risk perception & - \\
\hline & $\begin{array}{l}\text { Adoption of on-farm risk management } \\
\text { strategies }\end{array}$ & + \\
\hline & Adoption of risk-sharing strategies & + \\
\hline \multirow[t]{4}{*}{ Species } & SSI & $+/-$ \\
\hline & Risk perception & $+/-$ \\
\hline & $\begin{array}{l}\text { Adoption of on-farm risk management } \\
\text { strategies }\end{array}$ & $+/-$ \\
\hline & Adoption of risk-sharing strategies & $+/-$ \\
\hline
\end{tabular}

Notes: + positive expected influence, - negative expected influence, $+/-$ no prior.

Table 2

Sample size for each production system in three provinces in Vietnam.

\begin{tabular}{llllll}
\hline Province & \multicolumn{2}{l}{ Production system } & \multirow{2}{*}{ Total } \\
\cline { 2 - 5 } & $\begin{array}{l}\text { Intensive } \\
\text { shrimp }\end{array}$ & $\begin{array}{l}\text { Semi- } \\
\text { intensive } \\
\text { shrimp }\end{array}$ & $\begin{array}{l}\text { Improved } \\
\text { extensive } \\
\text { shrimp }\end{array}$ & $\begin{array}{l}\text { Integrated } \\
\text { mangrove - } \\
\text { shrimp }\end{array}$ & \\
\hline Soc Trang & 25 & 44 & 24 & 0 & 93 \\
Bac Lieu & 28 & 6 & 55 & 0 & 89 \\
Ca Mau & 44 & 1 & 40 & 46 & 131 \\
Total & 97 & 51 & 119 & 46 & 313
\end{tabular}

involve communication and coordination between multiple farmers and/or other actors (e.g. banks, insurers) to mitigate or prevent impacts from production risks.

Questions on production risk and risk management strategies were compiled based on the Aquaculture Stewardship Council (Aquaculture Stewardship Council, 2014) and Seafood Watch Standard (Monterey Bay Aquarium, 2016) for aquaculture. The lists of 16 production risks sources and 46 risk management strategies were then refined through 
Table 3

Descriptive statistics of selected farm and farmer characteristics in the sample.

\begin{tabular}{|c|c|c|c|c|c|c|c|}
\hline \multirow{2}{*}{\multicolumn{2}{|c|}{ Farmer and farm characteristics }} & \multirow[t]{3}{*}{ Unit } & \multicolumn{4}{|l|}{ Production system } & \multirow[t]{3}{*}{ Total } \\
\hline & & & Intensive shrimp & $\begin{array}{l}\text { Semi-intensive } \\
\text { shrimp }\end{array}$ & $\begin{array}{l}\text { Improved extensive } \\
\text { shrimp }\end{array}$ & $\begin{array}{l}\text { Integrated mangrove - } \\
\text { shrimp }\end{array}$ & \\
\hline & & & 97 & 51 & 119 & 46 & \\
\hline 1. & Age & Mean (sd) & $49.02(10.85)$ & $49.53(11.37)$ & $52.29(11.87)$ & $51.11(12.03)$ & $50.65(11.54)$ \\
\hline 2.1 & Shrimp experience & Mean (sd) & $13.38(6.39)$ & $16.96(7.45)^{(\mathrm{a})}$ & $15.64(5.23)^{\text {(a) }}$ & $19.02(8.68)^{(\mathrm{a})}$ & $15.65(6.80)$ \\
\hline 3. & Main shrimp area & Mean (sd) & $1.13(1.20)$ & $0.95(0.70)$ & $1.93(3.70)^{(\mathrm{a})}$ & $4.31(2.20)^{(\mathrm{a})}$ & $1.87(2.75)$ \\
\hline 4. & BS - risk attitude & Mean (sd) & 3.47 (1.07) & $3.11(0.88)$ & $3.07(1.22)$ & $3.28(1.25)$ & $3.23(1.14)$ \\
\hline 5. & Education & & & & (a) & (a) & \\
\hline \multicolumn{2}{|c|}{ Primary school } & $\%$ & 15.46 & 17.65 & 34.45 & 28.26 & 24.92 \\
\hline \multicolumn{2}{|c|}{ Secondary school } & $\%$ & 53.61 & 56.86 & 47.90 & 56.52 & 52.4 \\
\hline \multicolumn{2}{|c|}{ High school } & $\%$ & 25.77 & 23.53 & 10.92 & 15.22 & 18.21 \\
\hline \multicolumn{2}{|c|}{ College degree } & $\%$ & 2.06 & 0.00 & 3.36 & 0.00 & 1.92 \\
\hline \multicolumn{2}{|c|}{ University degree } & $\%$ & 3.08 & 1.96 & 3.36 & 0.00 & 2.56 \\
\hline \multicolumn{2}{|c|}{ Total } & $\%$ & 100.00 & 100.00 & 100.00 & 100.00 & 100.00 \\
\hline 6. & Membership of group & & & (a) & (a) & (a) & \\
\hline \multicolumn{2}{|c|}{ Cooperatives supported by NGOs } & $\%$ & 44.33 & 31.37 & 29.41 & 0.00 & 30.03 \\
\hline \multicolumn{2}{|c|}{ Cooperatives initiated by government } & $\%$ & 32.99 & 29.41 & 36.97 & 15.22 & 31.31 \\
\hline \multicolumn{2}{|c|}{ Individual farmers } & $\%$ & 22.68 & 39.22 & 33.61 & 88.78 & 38.66 \\
\hline \multicolumn{2}{|c|}{ Total } & $\%$ & 100.00 & 100.00 & 100.00 & 100.00 & 100.00 \\
\hline \multicolumn{2}{|r|}{ Shrimp species } & & & (a) & (a) & (a) & \\
\hline \multirow{2}{*}{\multicolumn{2}{|c|}{$\begin{array}{l}\text { Both } \\
\text { Vannamei }\end{array}$}} & $\%$ & 43.30 & 49.02 & 25.21 & 0.00 & 30.99 \\
\hline & & $\%$ & 44.33 & 41.18 & 12.61 & 0.00 & 25.24 \\
\hline \multicolumn{2}{|c|}{ Monodon } & $\%$ & 12.37 & 9.80 & 62.18 & 100.00 & 43.77 \\
\hline \multicolumn{2}{|c|}{ Total } & $\%$ & 100.00 & 100.00 & 100.00 & 100.00 & 100.00 \\
\hline
\end{tabular}

Notes: Standard deviation (sd) in parenthesis (a) Significant difference at $5 \%$ with intensive production system

the key literature relating to each production system in Vietnam (Bush et al., 2010; Ha et al., 2013; Joffre and Bosma, 2009). A set of 46 risk management strategies were categorized as either on-farm and shared, each with a number of sub-categories (see S4). In addition, questions were also asked on the personal characteristics of farmers, including age, experience, main shrimp area, risk attitude, education, group types, and shrimp species. Table 3 presents the descriptive statistics of selected characteristics of the farmers and their farm in the sample.

Additional data for the SSI was collected through a mapping exercise. Farmers were asked to draw their location relative to their main source of water and then identify the location of the (maximum) five surrounding farms with which they share this water source (based on the methodology employed by Bottema et al. (2019)). The number of five surrounding farms was chosen based on empirical information sourced from interviews with farmers before survey implementation. Using this map farmers then indicated the farms with which they shared information about farm management and who they interacted with socially. Farmers were asked about the average travel time (in minutes) on a motorbike to reach each of these farms. In addition, farmers were asked to evaluate their relationship with these farms on a three-point scale: 1 (weak), 2 (neutral), and 3 (strong). Further details on survey design and the SSI data collection are explained in supplementary materials S2.

\subsection{Socio-spatial index (SSI) construction}

We construct the SSI following the OECD (2008) framework for composite indicators. Based on the theoretical framework presented above and the data selection of the previous section (and noting there was no need for imputation of missing values), we combine the two dimension ratios of spatial and social connectivity into one composite index.

Based on the empirical data collected, the social connectivity ratio $\left(S O C I A L_{i}\right)$ was calculated for each farmer $i$ that shares water source with $J$ other farms as the equally weighted sum of the $K$ different production related risks discussed between farmers $P R_{i}=\sum_{j, k=1}^{J, K} P R_{j, k}$ divided by maximum number of risks possibly discussed $\max (P R)_{i}=6 * J$ and the sum of the $L$ different topics related to everyday social participation discussed between farmers $S P_{i}=\sum_{j, l=1}^{J, L} P R_{j, l}$ divided by its maximum number $\max (S P)_{i}=3 * J$ :

$\operatorname{SOCIAL}_{i}=0.5 * \frac{P R_{i}}{\max (P R)_{i}}+0.5 * \frac{S P_{i}}{\max (S P)_{i}}$

The spatial connectivity ratio (SPATIAL $L_{i}$ was calculated by deducting the average proximity to the $J$ other farms of each respondent $i$ measured in time travelled (Distance $_{i}=\sum_{j=1}^{J}$ distance $_{i, j} / J$ ) from the average proximity of the whole sample size $(20 \mathrm{~min})$. We used the average of the whole sample given the results of a MANOVA test did not reveal any differences between production systems (Table S.1). We determine that the higher the relative proximity the more coherent the definition of the socio-spatial area:

SPATIAL $_{i}=\left(20-\right.$ Distance $\left._{i}\right) / 20$

The final spatial connectivity ratio was normalized into a scale from 0 to $1-$ the higher the index the stronger the connectivity.

The final $S S I_{i}$ is the equally weighted average of both ratios:

$S S I_{i}=0.5 * S O C I A L_{i}+0.5 * S P A T I A L_{i}$

\subsection{Analytical methods}

All survey items were first checked for outliers, skewness and kurtosis. After inspecting and treating missing data, our sample size had 313 observations. We tested the internal reliability of risk perception, risk management strategies and risk attitude by using Cronbach Alpha. We tested the sample adequacy for perceived risk scores and risk attitudes by using the Kaiser-Meyer-Olkin (KMO) measures. Next, we performed exploratory and confirmatory factor analysis to reduce the number of variables in the survey related to sources of risk perception, risk management strategies and risk attitude to fewer but more meaningful latent variables. The factor extraction method used was principle component analysis. We decided to include items based on the loading factors $>0.4$ and significant $p<0.05$ (Kline, 2011). Then, we performed a structural equation modelling (SEM) by using these latent variables in our model to test the three hypotheses in Fig. 1. The 
following paragraphs described in more detail about factor analyses and SEM.

First, the perceived production risk scores were calculated by multiplying the scores of perceived probability and the impact of different production risk sources. Using the perceived risk scores, we performed an exploratory factor analysis for 16 risk perception sources to translate them into meaningful factors of production risks. However, only 14 perceived risk sources were reduced into five latent variables, the others were excluded due to loading factors $<0.4$.

Second, the adoption of 46 risk management strategies was measured on five-point Likert scales. These strategies were grouped into 6 sub-categories by taking the mean overall scores in each subcategory. On-farm risk management strategies include four sub-categories to avoid the impact of a risk like disease or poor water quality on their farm, namely: (1) risk prevention, (2) investment to reduce risk, (3) select less risky technology, and (4) diversification and flexibility. Risksharing strategies consist of two sub-categories named: (1) prevention and mitigation production risk strategies through cooperation with others (such as buying inputs together) and (2) prevention and mitigation production risks strategies through financial agreements (such as credit from banks or input suppliers to prevent or mitigate impacts from these risks). Based on these six sub-categories, we ran confirmatory factor analysis based on the maximum likelihood extraction method using the Satorra-Bentler estimator to confirm these sub-categories of the two latent variables named on-farm risk management and risksharing strategies.

Third, risk attitudes were measured by the four business statements method, which is used in many risk perception studies (Meuwissen et al., 2001; Bishu et al., 2018; Meraner and Finger, 2017). More details are provided in S2. Exploratory factor analysis was then performed to create one aggregated variable named risk attitude.

We applied structural equation modelling (SEM) to identify the different relationships among endogenous and exogenous variables and simultaneously tested the three hypotheses in Fig. 1. All the essential assumptions required in SEM were checked before developing a SEM model. Those latent variables achieving from exploratory and confirmatory factor analyses were used in our structural model (Fig. 2). The description of latent variables using in the SEM model were presented in Table 4. Following Accord (2014) to assess the fit of the model, we selected Comparative Fit Index (CFI) $>0.9$, the Root Mean Square of Error of Approximation (RMSEA) $<0.06$ and the Standardized Root Mean Square Residual (SRMR) $<0.05$. More specific details regarding to assumptions, missing data treatment, tests and model fit indexes are explained in supplementary materials S3.
Table 4

Description of the variables representing SEM constructs.

\begin{tabular}{ll}
\hline Construct and variables & Description of the variables \\
\hline $\begin{array}{c}\text { Perceived risk score of } \\
\text { Combines disease-water risk (DW) }\end{array}$ & $\begin{array}{l}\text { 1st month disease outbreak } \\
\text { Fluctuation of water temperature } \\
\text { Low dissolved oxygen } \\
\text { Algae death }\end{array}$ \\
2nd 3rd month disease outbreak \\
Disease risk (DR) & 4rd disease outbreak \\
& Slow growth shrimp disease \\
Controlled water risk (W1R) & Fast drop in water salinity in pond \\
& Algae blossom \\
Input risk (IR) & Excessive waste in pond \\
& Low quality of shrimp post larvae \\
Uncontrolled water risk (W2R) & Lack of PL reliable places to buy \\
& Increase in water salinity in pond \\
Adoption of risk management strategies & Pollution in common water resources \\
On-farm risk management & Risk prevention \\
strategies (OFRMS) & Investment to reduce risk \\
& Select less risky technology \\
Risk-sharing strategies (SS) & Diversification and flexibility \\
& Prevention and mitigation production risk \\
& by cooperation with farmers \\
& Prevention and mitigation production risk \\
through financial agreement
\end{tabular}

To test if variables are significantly different among different production systems, we performed MANOVA. We analysed the dataset by using STATA 14 (StataCorp 2015).

\section{Results}

\subsection{Dimensions of socio-spatial connectivity and socio-spatial index (SSI)}

The results show several significant differences between the key components of the SSI (see more details in Table S.1). However, the results also show that the SSI is not significantly different among production systems. This first indicates that, contrary to earlier studies (see Bush et al. (2010)), the degree of collaboration between farms is dependent on social relations and a spatial dimension regardless of the kind of production system. Second, it also indicates that the SSI provides a generic measure of the socio-spatial extent of shared risk management. As the SSI is determined by social measures-the potential and degree of information exchanged among farmers-it can be

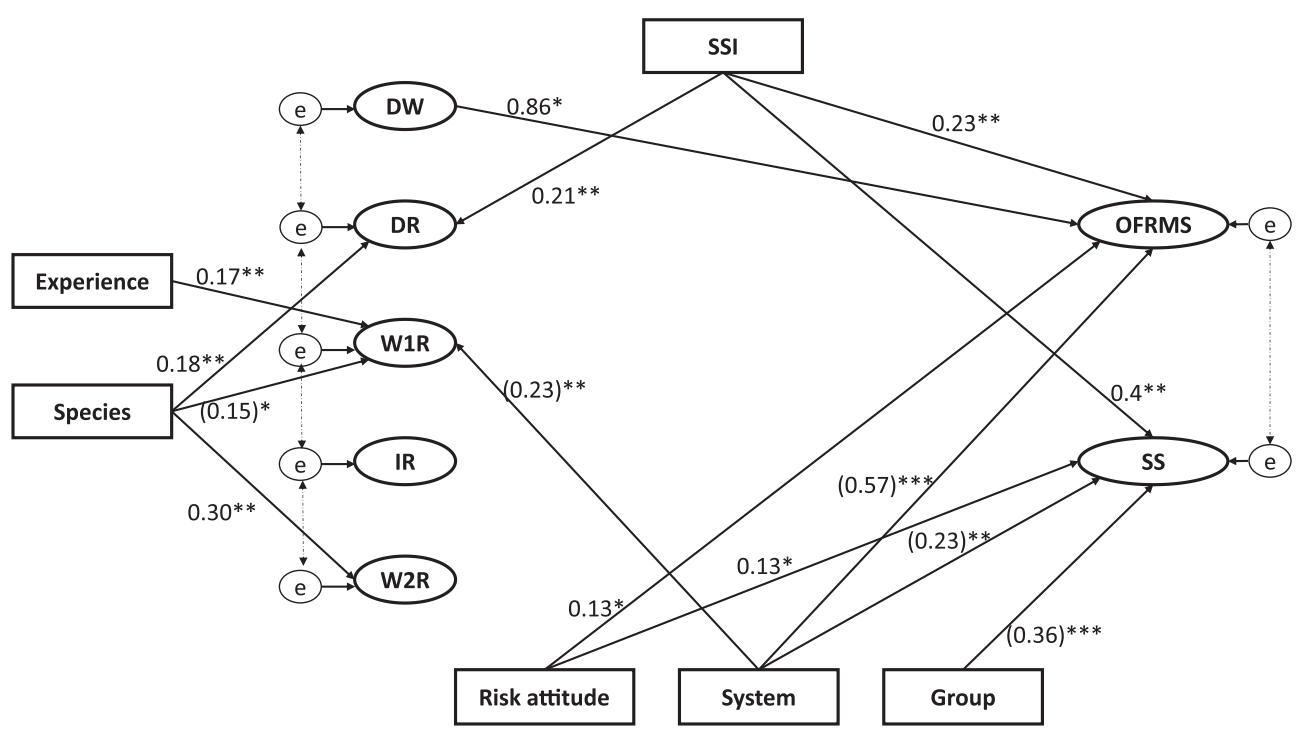

Fig. 2. Results of the SEM model for the adoption of on-farm risk management strategies and risk-sharing strategies. Significant levels: ${ }^{* * *} \mathrm{p}<0.001$, **p $<0.01$ and $* \mathrm{p}<0.05$. Broken lines indicate correlation, unbroken lines indicate structural relation in the direction of the arrow. The latent variables are shown in ovals, observed variables are shown in rectangles. Abbreviations of variables in the SEM model are described in Table 4. The numbers in brackets have negative values. 
measured regardless of the difference in biophysical dimension of land, coastal and marine aquaculture landscapes.

\subsection{Risk perception and risk management}

\subsubsection{Perceived production risk and risk attitude}

Exploratory factor analysis revealed five factors related to disease that shape the risk perception of farmers. First, "combined disease and water risk" brings together perceived disease risk within the first stocking month with water quality risk due to the changes in water temperature, dissolved oxygen and algae death in the pond. Second, "disease risk" represents the disease occurring one month after stocking. Third, "controlled water risk" represents changes to water indicators, such as salinity and algae blooms, that farmers can directly manage. Fourth, "input quality risks" combines the risk of low quality and lack of reliable places to buy good quality post larvae. Finally, "uncontrolled water risk" covers the perceived risk of water pollution from common water sources and salinity increase, which are beyond the ability of farmers to manage.

All five factors had eigenvalues higher than 1 and the total variance accounted for $58.42 \%$. The scree plot testing presents the appropriated model with five factors. We also confirm the model fit based on good model fit indices (see Table S.2). The factor loadings for risk attitude are all above 0.40 and the model fit indices indicate a good model fit (see Table S.3).

\subsubsection{Risk management strategies}

The results of the factor analysis validate the four sub-categories used to define on-farm risk management strategies and the two subcategories used for risk-sharing strategies (see Table S.4). Loading factors of each sub-category in the on-farm risk management and risksharing strategies are above 0.4 except for the risk-transfer strategies. This means that the risk-transfer strategies, such as yield insurance and finance, are unlikely to be adopted as shared risk management strategies among farmers - an observation supported by the virtual absence of insurance and access to finance in the shrimp sector (Nguyen and Jolly, 2019). Although the loading factor of risk-transfer strategies in the risk-sharing strategies' is only $0.28(<0.4)$, we decided to keep this sub-category because the model has good fit indices (see Table S.4).

\subsection{Associations between the SSI and risk perception and risk management strategies}

The SEM model explores the associations between the SSI, production risk perceptions and risk management strategies. It also analyses the factors affecting the adoption of risk management strategies namely: risk attitude, production system, species, age, education, experience and group types. The results are shown in Fig. 2. The model has good fit indices, which means that our SEM is an appropriate model to explain the relationship among SSI, risk perception and risk management strategies (Table 5).

As expected, the results in Table 5 confirm a positive association between SSI and perception of disease risk with a significant coefficient (0.21) (see H1). This means that a high SSI, corresponding to high degree of socio-spatial connectivity among farmers sharing common water resources, plays a role in shaping the perceived risk of disease.

The results in Table 5 also confirm a positive relation between the SSI and the adoption of both on-farm (0.23) and shared risk management strategies (0.4) (H2). This indicates that the more information that is exchanged among farmers sharing a source of water the greater the uptake of risk management strategies in general.

We expected to find a positive association between risk perception and risk management strategies (H3). However, the five perceived production risk factors were neither found to be associated with the adoption of on-farm nor shared risk management strategies. Only the perceived relationship between "combined disease and water risk" was found to have a positive and signification relationship with the adoption of on-farm risk management (Table 5). Based on these results hypothesis $\mathrm{H} 3$ is rejected.

Finally, production system, species and membership of groups are all found to associate with farmer's risk behaviour (as observed by Joffre et al., 2018b; van Winsen et al., 2016; Ahsan, 2011). We observe that farmers who have a high degree of socio-spatial connectivity (i.e. with a higher SSI) appear less likely to be a member of a group. In addition, the degree of information shared among this network directly influences a farmer's adoption regardless the intensity of the production system. This indicates that membership of groups plays a role in determining the adoption of risk-sharing strategies among farmers and, reflecting Meuwissen et al. (2019), opens up opportunities for groupbased contracts for risk-sharing.

\section{Discussion}

The results confirm that the SSI can be used to define the spatial extent of shared risk management strategies for shrimp aquaculture. We find that the spatial extent of area-based management is, as expected, directly related to the amount of information shared between farmers using a common water source and is at least as important as the risk attitude of farmers or other characteristics of farms and farmers for determining the adoption of risk management strategies. We also find that a higher SSI associates with the higher awareness of disease-water risks and the higher adoption of risk management strategies. Conversely, a lower SSI indicates that the less information shared, the weaker the perceived risk, and the less likely shared risks strategies will be adopted. Finally, we find a weak relationship between risk perception and the adoption of risk management. However, we also observe that risk perception is more likely to have an indirect relationship on risk behaviour as measured by the SSI. As argued by Bottema et al. (2019), this is because socio-spatial communication and collaboration may stimulate the adoption of shared risk management and in doing so override the influence of individual perceptions of on-farm risk management strategies.

We argue that the SSI responds directly to calls for relational approaches to landscape or area-based management/governance (Arts et al., 2017; Bottema et al., 2019) by providing a quantitative predictor of the scale at which farmers will most likely invest in the shared management of production risks. By defining the spatial extent of shared risk management based on social and spatial connectivity the SSI provides a fundamentally different starting point to determining the scale at which management is best enacted. For example, current measures and tools for spatial planning related to aquaculture are based on conflict resolution, macro-economic and conservation planning (Henriques et al., 2017), dispersion models of effluents and/or disease vectors (Murray and Gubbins, 2016), or biophysical modelling (Adams et al., 2016; Bannister et al., 2016). The SSI challenges these approaches by incorporating a social measure of management boundaries based on where when and how farmers coordinate their action based on shared meaning and perceptions of risk.

The results also show that regardless the different average distances between farms in the four production systems (ranging from 1 to $20 \mathrm{~min}$ ), there was no significant difference in the SSI index among these systems (Table S.1). This indicates that the relational space between farmers, based on information sharing, can be considered spatially 'elastic' - with the potential to expand and retract over Euclidean distance between farms dependent on social connectivity. This means that although our study is delimited to farmers sharing a common water source (following Bottema et al. (2019) and Murray and Gubbins (2016)), the SSI appears likely to remain useful over landscapes that extend beyond the catchment of shared water sources. It also means, however, that further research is needed to determine just how elastic SSI-based delimitation of management areas are given different degrees of social connectivity that we found in the case of Vietnamese shrimp 
Table 5

Standardized SEM coefficients including all variables related to the SSI, risk perception and risk management strategies.

\begin{tabular}{|c|c|c|c|c|c|c|c|c|}
\hline \multirow[t]{2}{*}{ SEM variables } & \multirow[t]{2}{*}{ SSI } & \multicolumn{5}{|l|}{ Risk perception } & \multicolumn{2}{|c|}{ Risk management strategies } \\
\hline & & Disease-water risk & Disease risk & Controlled water risk & Input risk & Uncontrolled water risk & On-farm & Sharing \\
\hline SSI & & 0.07 & $0.21^{* *}$ & 0.12 & 0.01 & 0.07 & $0.23^{* *}$ & $0.4^{* * * *}$ \\
\hline Risk attitude & 0.35 & 0.08 & $(0.06)$ & 0.03 & $(0.01)$ & 0.07 & $0.13^{*}$ & $0.13^{*}$ \\
\hline \multicolumn{9}{|l|}{ Farm characteristics } \\
\hline Production system & 0.04 & $(0.09)$ & $(0.06)$ & $(0.23)^{* * *}$ & $(0.03)$ & 0.06 & $(0.57)^{* * * * *}$ & $(0.23)^{* *}$ \\
\hline Species & $(0.11)$ & $(0.12)$ & $0.18^{* * *}$ & $(0.15)^{*}$ & 0.10 & $0.30^{* *}$ & 0.12 & 0.08 \\
\hline \multicolumn{9}{|l|}{ Farmer characteristics } \\
\hline Age & 0.05 & $(0.05)$ & $(0.05)$ & $(0.11)$ & $(0.05)$ & 0.03 & 0.01 & 0.02 \\
\hline Education & 0.05 & $(0.10)$ & $(0.07)$ & $(0.05)$ & $(0.03)$ & 0.04 & 0.13 & 0.11 \\
\hline Experience & 0.08 & 0.11 & 0.08 & $0.17^{* * *}$ & 0.07 & $(0.04)$ & 0.01 & 0.07 \\
\hline Membership of group & $(0.08)$ & 0.01 & 0.09 & $(0.11)$ & 0.01 & 0.01 & $(0.54)$ & $(0.36)^{* * *}$ \\
\hline \multicolumn{9}{|l|}{ Risk perception } \\
\hline Disease - water risk & & & & & & & $0.86^{*}$ & 0.67 \\
\hline Disease risk & & & & & & & $(0.41)$ & $(0.31)$ \\
\hline Controlled water risk & & & & & & & $(0.15)$ & $(0.13)$ \\
\hline Input risk & & & & & & & $(0.10)$ & $(0.16)$ \\
\hline Uncontrolled water risk & & & & & & & $(0.28)$ & $(0.19)$ \\
\hline
\end{tabular}

Model fit indices S-B $\chi^{2}=1881.371$ ( $\left.\mathrm{p}<0.0001\right)$, df $=357$, RMSEA_SB $=0.042$, CFI_SB $=0.91$ and SRMR $=0.049$.

Abbreviations are explained in Table 4. Numbers between brackets implies negative values.

*** $\mathrm{p}<0.001$.

** $\mathrm{p}<0.01$.

$* \mathrm{p}<0.05$.

production (i.e. five surrounding farms). This research should also explore how variations in methodology influence the sensitivity on the model results under different conditions of area management that extend to both inland and marine (cage-culture) production systems (starting, for instance, with the AMA systems reported on by Murray and Gubbins (2016)). Linked to this, further research is also needed to assess the ability of the SSI to predict farmer collaboration for managing shared risks across different landscaped and spatial scales.

Expanding the SSI to inland and marine production systems would require further research on the different risk perception, attitudes and strategies of farmers for species other than shrimp. The different risk profiles of other species would lead to more or less information shared among farmers which would affect the application and calculation of the SSI. Overall, however, comparison between the type and volume of information communicated between farmers producing these different species would enhance the comprehensiveness and generalizability of the SSI. Similarly, further qualitative analysis based on different production systems would also empirically validate whether the social and spatial connectivity can be assumed to have equal weight as we have done for the case of shrimp.

Once further developed, the SSI has the potential to refine existing area-management approaches as well as open up new approaches for shared risk management within these areas. Existing area management can be enhanced, for instance, by more effectively predicting the spatial extent, or area, within which shared risk management may be most effectively implemented (Meuwissen et al., 2013). New risk management approaches using the SSI are expected to face less problems of asymmetric information as risk-sharing mechanisms such as insurance and group contracts are better aligned to the social (and therefore informational) networks within a given area. For instance, if a group of farmers has a high SSI, indicating a higher flow of information between farmers and increased probability of shared risk management strategies, there may be a lower probability for incorporating poor performers (adverse selection) and/or less change of riskier behaviour after risk transfer arrangements have been put in place (moral hazard). As suggested by Bush et al. (2019), this can in turn provide impetus for the development of new forms of assurance among farmers, and between farmers and insurers, banks and international buyers.

\section{Conclusions}

The SSI introduced in this paper provides one of the first objective measures for determining the spatial extent of shared risk management in a given farming area or landscape. More fundamentally the SSI also provides insights into how shared and selected individual risk perception translate into shared risk behaviour. In doing so the SSI enables an alternative socio-spatial measure for defining the areal extent of shared risk behaviour that goes beyond the predominant focus in research and practice on individual farm-level risk management strategies.

The SSI is as such applicable for predicting the spatial extent of existing production risk-sharing strategies, as well as designing area or landscape-based management. In any potential application, the SSI stresses the importance of social networks among farmers in determining the scale at which boundaries around spatial connectivity across landscapes can be defined. As such, the SSI can be generalized beyond aquaculture to any attempt to develop spatially explicit forms of primary production or natural resource use that requires the mitigation of shared risk. Before being translated into practice, further development of the SSI is needed, either in the design of new area-based management approaches or the reform of existing approaches, by assessing its relevance and accuracy across a range of different empirical contexts.

\section{Author agreement statement}

We the undersigned declare that this manuscript is original, has not been published before and is not currently being considered for publication elsewhere.

We confirm that the manuscript has been read and approved by all named authors and that there are no other persons who satisfied the criteria for authorship but are not listed. We further confirm that the order of authors listed in the manuscript has been approved by all of us.

We understand that the Corresponding Author is the sole contact for the Editorial process.

She is responsible for communicating with the other authors about progress, submissions of revisions and final approval of proofs. 


\section{Declaration of Competing Interest}

The authors declare no conflicts of interest.

\section{Acknowledgements}

We thank all respondents who participated in the research. We would also like to express our appreciations to Vu Duc Hung, Dinh Xuan Lap, Ho Minh Phong, Tang Thanh Chi and Dang Kieu Nhan and Vo Thi Thanh Loc for their input to the development and execution of the survey. We also thank staff at DARD for facilitating access to respondents. This research has been conducted through the SUPERSEAS program funded by the Netherlands Organization for Scientific Research's Food and Business Global Challenges Program (W 08.250.2051).

\section{Appendix A. Supplementary data}

Supplementary data to this article can be found online at https:// doi.org/10.1016/j.aquaculture.2020.735861.

\section{References}

Accord, A.C., 2014. A Gentle Introduction to Stata. StataCorp LP, College Station, Texas. Adams, T.P., Aleynik, D., Black, K.D., 2016. Temporal variability in sea lice population connectivity and implications for regional management protocols. Aquacul. Env. Interac. 8, 585-596.

Aguilar-Manjarrez, J., Soto, D., Brummett, R., 2017. Aquaculture zoning, site selection and area management under the ecosystem approach to aquaculture. In: A Handbook. Food and Agriculture Organization of the United Nations (FAO), Rome.

Ahsan, D.A., 2011. Farmers' motivations, risk perceptions and risk management strategies in a developing economy: Bangladesh experience. J. Risk Res. 14 (3), 325-349.

Ahsan, D.A., Roth, E., 2010. Farmers' perceived risks and risk management strategies in an emerging mussel aquaculture industry in Denmark. Mar. Resour. Econ. 25 (3), 309-323.

Allen, K.E., Quinn, C.E., English, C., Quinn, J.E., 2018. Relational values in agroecosystem governance. Curr. Opin. Environ. Sustain. 35, 108-115.

Anh, P.T., Kroeze, C., Bush, S.R., Mol, A.P.J., 2010. Water pollution by intensive brackish shrimp farming in south-East Vietnam: causes and options for control. Agric. Water Manag. 97 (6), 872-882.

Aquaculture Stewardship Council, 2014. ASC Shrimp Standard. pp. 144.

Arts, B., Buizer, M., Horlings, L., Ingram, V., van Oosten, C., Opdam, P., 2017. Landscape approaches: a state-of-the-art review. Annu. Rev. Environ. Resour. 42 (1), 439-463.

Bannister, R.J., Johnsen, I.A., Hansen, P.K., Kutti, T., Asplin, L., 2016. Near- and far-field dispersal modelling of organic waste from Atlantic salmon aquaculture in fjord systems. ICES J. Mar. Sci. 73 (9), 2408-2419.

Bear, C., 2013. Assembling the sea: materiality, movement and regulatory practices in the Cardigan Bay scallop fishery. Cult. Geogr. 20 (1), 21-41.

Benhabib, J., Bisin, A., Jackson, M.O., 2011. Handbook of Social Economics. Elsevier/ North-Holland, Amsterdam.

Bergfjord, O.J., 2009. Risk perception and risk management in Norwegian aquaculture. J. Risk Res. 12 (1), 91-104.

Bishu, K.G., O'Reilly, S., Lahiff, E., Steiner, B., 2018. Cattle farmers' perceptions of risk and risk management strategies: evidence from northern Ethiopia. J. Risk Res. 21 (5), 579-598.

Bottema, M.J.M., Bush, S.R., Oosterveer, P., 2019. Moving beyond the shrimp farm: spaces of shared environmental risk? Geogr. J. 185 (2), 168-179.

Bush, S.R., van Zwieten, P.A., Visser, L., van Dijk, H., Bosma, R., de Boer, W.F., Verdegem, M., 2010. Scenarios for resilient shrimp aquaculture in tropical coastal areas. Ecol. Soc. 15 (2), 15.

Bush, S.R., Oosterveer, P., Bottema, M., Meuwissen, M., Mey, d.Y., Chamsai, S., Lien, H.H., Chadag, M., 2019. Inclusive environmental performance through 'beyond-farm' aquaculture governance. Curr. Opin. Environ. Sustain. 41, 49-55.

FAO, 2018. The State of World Fisheries and Aquaculture 2018 - Meeting the Sustainable Development Goals. (Rome).

Fischer, A.P., Klooster, A., Cirhigiri, L., 2019. Cross-boundary cooperation for landscape management: collective action and social exchange among individual private forest landowners. Landsc. Urban Plan. 188, 151-162.

Freeman, O.E., Duguma, L.A., Minang, P.A., 2015. Operationalizing the integrated landscape approach in practice. Ecol. Soc. 20 (1).

Galappaththi, E.K., Berkes, F., 2015. Can co-management emerge spontaneously? Collaborative management in Sri Lankan shrimp aquaculture. Mar. Policy 60, 1-8.

Ha, T.T.T., Bush, S.R., van Dijk, H., 2013. The cluster panacea?: questioning the role of cooperative shrimp aquaculture in Vietnam. Aquaculture 388, 89-98.

Hardaker, J.B., Lien, G., Anderson, J.R., Huirne, R.B., 2015. Coping with Risk in Agriculture: Applied Decision Analysis. CABI.
Henriques, N.S., Monteiro, P., Bentes, L., Oliveira, F., Afonso, C.M.L., Gonçalves, J.M.S., 2017. Marxan as a zoning tool for development and economic purposed areas Aquaculture Management Areas (AMAs). Ocean Coast. Manag. 141, 90-97.

Hunecke, C., Engler, A., Jara-Rojas, R., Poortvliet, P.M., 2017. Understanding the role of social capital in adoption decisions: an application to irrigation technology. Agric. Syst. 153, 221-231.

Joffre, O.M., Bosma, R.H., 2009. Typology of shrimp farming in Bac Lieu Province, Mekong Delta, using multivariate statistics. Agric. Ecosyst. Environ. 132 (1-2), $153-159$.

Joffre, O.M., Klerkx, L., Khoa, T.N.D., 2018a. Aquaculture innovation system analysis of transition to sustainable intensification in shrimp farming. Agron. Sustain. Dev. 38 (3), 1-11.

Joffre, O.M., Poortvliet, P.M., Klerkx, L., 2018b. Are shrimp farmers actual gamblers? An analysis of risk perception and risk management behaviors among shrimp farmers in the Mekong Delta. Aquaculture 495, 528-537.

Joffre, O.M., Poortvliet, P.M., Klerkx, L., 2019. To cluster or not to cluster farmers? Influences on network interactions, risk perceptions, and adoption of aquaculture practices. Agric. Syst. 173, 151-160.

Kamstra, P., Cook, B., Edensor, T., Kennedy, D.M., 2019. Re-casting experience and risk along rocky coasts: a relational analysis using qualitative GIS. Geogr. J. 185 (1), 111-124.

Kline, R.B., 2011. Principles and Practice of Structural Equation Modeling, 3rd ed. Guilford Press, New York, NY, US.

Le, T.C., Cheong, F., 2010. Perceptions of risk and risk management in Vietnammese catfish farming: an empirical study. Aquacult. Econ. Manage. 14 (4), 282-314.

Lebel, L., Lebel, P., Lebel, B., 2016. Impacts, perceptions and management of climaterelated risks to cage aquaculture in the reservoirs of Northern Thailand. Environ. Manag. 58 (6), 931-945.

Massey, D.B., 2005. For Space. SAGE, London.

Matous, P., 2017. Complementarity and substitution between physical and virtual travel for instrumental information sharing in remote rural regions: a social network approach. Transp. Res. A 99, 61-79.

Matous, P., Todo, Y., Pratiwi, A., 2015. The role of motorized transport and mobile phones in the diffusion of agricultural information in Tanggamus regency, Indonesia. Transportation 42 (5), 771-790.

Meraner, M., Finger, R., 2017. Risk perceptions, preferences and management strategies: evidence from a case study using German livestock farmers. J. Risk Res. 1-26.

Meuwissen, M., Huirne, R., Hardaker, J., 2001. Risk and risk management: an empirical analysis of Dutch livestock farmers. Livest. Prod. Sci. 69 (1), 43-53.

Meuwissen, M.P.M., Assefa, T.T., van Asseldonk, M.A.P.M., 2013. Supporting insurance in european agriculture: experience of mutuals in the Netherlands. EuroChoices 12 (3), 10-16.

Meuwissen, M.P.M., Bottema, M.J.M., Hong Ho, L., Chamsai, S., Manjur, K., de Mey, Y., 2019. The role of group-based contracts for risk-sharing; what are the opportunities to cover catastrophic risk? Curr. Opin. Environ. Sustain. 41, 80-84.

Monterey Bay Aquarium, 2016. Seafood Watch Standard for Aquaculture, Version A3.2. Monterey Bay Aquarium.

Murray, A.G., Gubbins, M., 2016. Spatial management measures for disease mitigation as practiced in Scottish aquaculture. Mar. Policy 70, 93-100.

Nguyen, K.A.T., Jolly, C.M., 2019. Steps toward the establishment of a commercial aquaculture insurance program: lessons from an assessment of the Vietnamese pilot insurance program. Rev. Fish. Sci. Aquac. 27 (1), 72-87.

OECD, 2008. Handbook on Constructing Composite Indicators: Methodology and UserGuide.

Salama, N.K.G., Murray, A.G., Rabe, B., 2016. Simulated environmental transport distances of Lepeophtheirus salmonis in Loch Linnhe, Scotland, for informing aquaculture area management structures. J. Fish Dis. 39 (4), 419-428.

Soto, D., Aguilar-Manjarrez, J., Brugère, C., Angel, D., Bailey, C., Black, K., Edwards, P., Costa-Pierce, B., Chopin, T., Deudero, S., 2008. Applying an ecosystem-based approach to aquaculture: principles, scales and some management measures. Build. Ecosyst. Appr. Aquacu. 14.

StataCorp, 2015. Stata Statistical Software: Release 14. StataCorp LP, College Station, TX.

Subasinghe, R., Soto, D., Jia, J., 2009. Global aquaculture and its role in sustainable development. Rev. Aquac. 1 (1), 2-9.

Thitamadee, S., Prachumwat, A., Srisala, J., Jaroenlak, P., Salachan, P.V., Sritunyalucksana, K., Flegel, T.W., Itsathitphaisarn, O., 2016. Review of current disease threats for cultivated penaeid shrimp in Asia. Aquaculture 452, 69-87.

Tomich, T.P., Brodt, S., Ferris, H., Galt, R., Horwath, W.R., Kebreab, E., Leveau, J.H.J., Liptzin, D., Lubell, M., Merel, P., Michelmore, R., Rosenstock, T., Scow, K., Six, J., Williams, N., Yang, L., 2011. Agroecology: a review from a global-change perspective. Annu. Rev. Environ. Resour. 36, 193-222.

Umesh, N., Mohan, A.C., Ravibabu, G., Padiyar, P., Phillips, M., Mohan, C., Bhat, B.V., 2010. Shrimp Farmers in India: Empowering Small-Scale Farmers Through a ClusterBased Approach. Success Stories in Asian aquaculture Springer, pp. 41-66.

van Koppen, C.S.A., Bush, S.R., 2018. Spatial frames and the quest for institutional fit. In: Boström, M., Davidson, D.J. (Eds.), Environment and Society: Concepts and Challenges. Springer International Publishing, Cham, pp. 305-326.

van Winsen, F., de Mey, Y., Lauwers, L., Van Passel, S., Vancauteren, M., Wauters, E., 2016. Determinants of risk behaviour: effects of perceived risks and risk attitude on farmer's adoption of risk management strategies. J. Risk Res. 19 (1), 56-78.

Vandergeest, P., Ponte, S., Bush, S., 2015. Assembling sustainable territories : space, subjects, objects, and expertise in seafood certification. Environ. Plan. A 47 (2015), 9. 